\title{
Proliferation Markers, Remodeling Factors, Cytokines, Antimicrobial Peptides and Gene Proteins in Cholesteatoma
}

\author{
Kristaps Dambergs*1 ${ }^{* 1}$ Gunta Sumeraga ${ }^{1}$ and Māra Pilmane ${ }^{2}$ \\ ${ }^{1}$ Department of Otorhinolaryngology, Riga Stradins University, Pilsonu street 13 LV-1002, Riga, Latvia \\ ${ }^{2}$ Institute of Anatomy and Anthropology, Riga Stradins University, Kronvalda Boulevard 9, LV-1010 Riga, Latvia
}

*Corresponding author: Kristaps Dambergs, Department of Otorhinolaryngology, Riga Stradins University, Pilsonu street 13 LV-

1002, Riga, Latvia

\section{ARTICLE INFO}

Received: 慧 December 03, 2019

Published: 慧January 07, 2020

Citation: Kristaps Dambergs, Gunta Sumeraga, Māra Pilmane. Proliferation Markers, Remodeling Factors, Cytokines, Antimicrobial Peptides and Gene Proteins in Cholesteatoma. Biomed J Sci \& Tech Res 24(2)-2020. BJSTR. MS.ID.004039.

Keywords: Cholesteatoma; Proliferation Marker; Remodeling Factors; Cytokines; Human Beta Defensins; Gene

Abbreviations: MMPs: Matrix Metalloproteinases; TIMPs: Tissue Inhibitors of Metalloproteinases; Shh: Sonic Hedgehog; IMH: Immunohistochemistry

\section{ABSTRACT}

Introduction: The complex appearance of proliferation markers, cytokines, remodelling factors, antimicrobial peptides and genes still have not been studied together despite their possible crucial role in the development of cholesteatoma. Therefore, the aim of this study was complex research of appearance and distribution of proliferation, remodeling markers, pro- and anti-inflammatory cytokines, local tissue defensins and genes of the cholesteatoma tissue.

Materials and Methods: Four cholesteatoma tissue samples were obtained from children, 5 cholesteatoma specimens were obtained from adults, and 7 deep external meatal skin controls were obtained from cadavers. Tissues were stained for Ki-67,

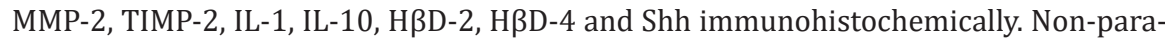
metric statistic, Mann-Whitney and Spearman's coefficient were used.

Results: A statistically significant difference was seen between the numbers of Ki67, TIMP-2 positive cells in matrix and control group epithelium and between numbers of H $\beta D-2, H \beta D-4$ Shh positive cells in perimatrix in comparison to control group connective tissue. A very strong positive correlation was detected in control tissue epithelium between Ki-67 and TIMP-2, IL-10, Shh; between MMP-2 and TIMP-2, IL-1; between IL-10 and TIMP-2, Shh. In the connective tissue, a very strong correlation was detected between Ki-67 and Shh. A strong correlation was detected in epithelium between Ki-67 and MMP-2, and between MMP-2 and IL-10.

Conclusion: Cholesteatoma tissue with the low appearance of Ki-67 proves the indistinct proliferation activity in the already developed tumour, but Ki-67 correlations with $\mathrm{H} \beta \mathrm{D}-2$ and $\mathrm{H} \beta \mathrm{D}-4$ in cholesteatoma indicate the direct link between the proliferation and expression of antimicrobial peptides. H $\beta D-2$ seems to be the most important

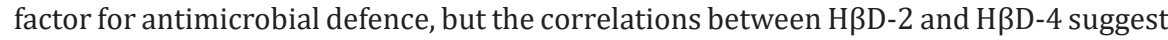
their common action against chronic middle ear infection in case of choleasteatoma. Higher levels of MMP-2 positive cells in cholesteatoma and lower levels of TIMP-2 positive cells suggest the prevalence of enzymatic processes over their suppression, possibly being characteristic for cholesteatoma of different age patients. Shh gene might play a crucial role in the development of cholesteatoma.

\section{Introduction}

Cholesteatoma is a benign lesion found in the middle ear [1,2] Incidence of cholesteatoma is 3:100,000 in children and 9.2:100,000 in the adult population, in males 1.4 times more often than females [3]. Cholesteatoma is characterized with a local inflammatory and osteolytic process, it consists of three layers: cystic layer, matrix and perimatrix. The cystic layer is composed of an anucleate keratin mass with epithelial debris. The matrix contains the same layers as normal skin, perimatrix - mainly inflammatory cells 
which induce osteolytic process in surrounding bone [4]. If left untreated, cholesteatoma might cause severe complications as facial nerve paralysis, hearing loss, intracranial infections like meningitis and brain abscess, also the destruction of inner ear [5]. All of these complications affect quality of life of patients. The ontogenetic change in cholesteatoma is not yet understood, and it is the reason for ongoing interest from scientists and surgeons in different developmental stages of cholesteatoma. Also, the complex research with a correlation of different tissue factors is not yet done in cholesteatoma. From all, those with proliferation, remodeling, stimulating and suppressing inflammation, tissue defence and entodermal genes are of interest for researchers.

So, to evaluate tissue proliferation, Ki-67 is used. It presents in all phases of the cell cycle except G0. Ki-67 is located in the cell nucleus and is showed in all proliferative cells [6], therefore, is proven to be useful in cholesteatoma tissue and demonstrate hyperproliferative process in keratin cells of cholesteatoma [7]. Cholesteatoma tissue induces remodelling factors resulting as local temporal bone osteolysis [8]. These are matrix metalloproteinases (MMPs), which are a family of zinc and calcium-dependent proteinases that are responsible for tissue remodelling, cell adhesion, migration, and also proliferation. MMPs regulate the activity of nonextracellular matrix proteins, such as growth factors, cytokines, cell receptors and other MMPs [9-12]. MMP-2 is believed to be the most important remodelling factor to cause bone erosion [13]. There are still controversies whether MMPs are more active in cholesteatoma tissue than in control tissue [14]. Banerjee et al. [13] states that there is no difference in cholesteatoma from the control tissue, but Dornelles et al. [14] proved that MMP-2 is more actively expressed in cholesteatoma than in control tissue. MMPs are inhibited by tissue inhibitors of metalloproteinases (TIMPs) [15]. Even though TIMPs are proven to be the regulators of MMPs, there are almost no studies about MMPs and TIMPs correlation in cholesteatoma.

The perimatrix of cholesteatoma contains inflammatory cells - monocytes, lymphocytes, fibroblasts, endothelial cells that emit proinflammatory and immunoregulatory cytokines like interleukin (IL)-1 and IL-10. It is believed that cytokines that are present in cholesteatoma can induce cell proliferation in the basal layer of matrix, releasing resorptive enzymes and therefore inducing osteolysis [16-19]. Tissue proinflammatory cytokine IL-1 is one of the factors that is responsible for aggressiveness of cholesteatoma. IL-10 is known to inhibit the inflammatory process [20]. It has been suggested that IL-10 possesses antiosteoclastogenic activities in cholesteatoma [18], and that is why the correlation between IL-1 and IL-10 should be evaluated. Chronic middle ear infection with cholesteatoma is mainly characterised by Paeruginosa infection [21]. Human beta defensin (HBD)-2 is secreted as a defence factor against P.aeruginosa infection [22]. Park et al. [23] proved that H $\beta D$ 2 is overexpressed in cholesteatoma matrix compared to external ear canal skin epithelium. However, nothing is known about HßD-4 role in cholesteatoma tissue. Not only in otology, but also in other fields of medicine, not much is known about HBD-4 [24].

$\mathrm{H} \beta \mathrm{D}-4$ is believed to be a stronger antibacterial peptide against P.aeruginosa [25] than H $\beta \mathrm{D}-2$. Also, it might play a different role in infection than other defensins and is proven to upregulate other defensins in the inflammation process $[26,27]$. The main theory is that cholesteatoma arises from epithelium which migrates from external ear canal to middle ear [28]. External ear, however, develops from 1st and 2nd pharyngeal pouch [29] that is regulated by Sonic hedgehog (Shh) gene and protein. Shh plays a critical role in the development of $1^{\text {st }}$ pharyngeal arch [30-32] from which external ear canal arises [33] and from where epithelium migrates to form cholesteatoma. There is no information in scientific databases whether Shh is important in the ontogenesis of cholesteatoma, and there is limited information about Shh gene and external ear development. The aim of this study was complex research of appearance and distribution of proliferation (Ki-67) and remodelling markers (MMP-2, TIMP-2), pro- and anti-inflammatory cytokines (IL-1, IL-10), local tissue defensins (H $\beta D-2, H \beta D-4)$ and genes (Shh) of the cholesteatoma tissue.

\section{Material and Methods}

\section{Tissue Samples}

Cholesteatoma specimens were retrieved during cholesteatoma surgery in Children's Clinical University Hospital and P. Stradins Clinical University Hospital, but the study was conducted at the Department of Morphology of the Riga Stradins University, Latvia. Four cholesteatoma tissue samples were obtained from children - 3 male, 1 female (age 9-17 years, mean age 13.25 years). Five cholesteatoma specimens were obtained from adults - 2 male, 3 female patients (age 23-75 years, mean age 48 years). Seven deep external meatal skin controls were obtained from cadavers in a collection of Institute of Anatomy and Anthropology. This study was approved by the local Ethical Committee of the Riga Stradins University (05.09.2019; Nr.6-2/7/4).

\section{Immunohistochemical Analysis}

Tissues were fixed in a mixture of $2 \%$ formaldehyde and $0.2 \%$ picric acid in 0.1 M phosphate buffer ( $\mathrm{pH} 7.2$ ). Afterwards, they were rinsed in Tyrode buffer (content: $\mathrm{NaCl}, \mathrm{KCl}, \mathrm{CaCl}_{2-} 2 \mathrm{H} 2 \mathrm{O}, \mathrm{MgCl} 2{ }_{-} 6 \mathrm{H}_{2} \mathrm{O}$, $\mathrm{NaHCO}_{3}, \mathrm{NaH}_{2} \mathrm{PO}_{4-} \mathrm{H}_{2} \mathrm{O}$, glucose) containing $10 \%$ saccharose for 12 $\mathrm{h}$ and then embedded into the paraffin. Three micrometers thin sections were cut, which were then stained with hematoxylin and eosin for routine morphological evaluation. Biotin-Streptavidin biochemical method was used for immunohistochemistry (IMH) to detect: Ki67 (1508202A, working dilution 1:100, Sigma-Aldrich, St. Louis, MO, USA), MMP-2 (cat; No AF902, LOT DUBO 34081, obtained from goat, 1:100 dilution, R\&D Systems, Germany), TIMP-2 (cat; No 3A4, sc - 21735, obtained from mouse, 1:200 dilution, Santa Cruz Biotechnology, INC), IL-1 (orb308737, working dilution 1:100, Biorbyt Limited, Cambridge, UK), IL-10 (250713, working dilution 
1:100, BioSite, Täby, Sweden), h $\beta D-2$ (goat; 1:100; Bio-Techne, UK), hßD-4 (mouse; 1:100; Santa Cruz Biotechnology, USA), Shh (mouse; AF 464, working dilution 1:60, R\&D Systems, Germany).

The slides were analyzed by light microscopy using nonparametric evaluation. The results were evaluated by grading the appearance of positively stained cells in the visual field [34]. Structures in the visual field were labelled as follows: $0-$ no positive structures, $0 /+-$ occasional positive structures, + - few positive structures, $+/++$ - few to moderate number of positive structures, ++- moderate number of positive structures, $++/+++-$ moderate to numerous positive structures, +++- numerous positive structures, +++++++ numerous to abundant structures, ++++-abundance of positive structures in the visual field. For a visual illustration, Leica DC 300F digital camera and image processing and analysis software Image Pro Plus (Media Cybernetics, Inc., Rockville, MD, USA) were used.

\section{Statistical Analysis}

The data processing was performed with SPSS software, version 22.0 (IBM Company, Chicago, IL, USA). Spearman's rank correlation coefficient was used to determine correlations between factors, where $r=0-0.2$ was assumed as a very weak correlation, $r$ $=0.2-0.4-$ a weak correlation, $r=0.4-0.6-$ a moderate correlation, $r=0.6-0.8-a$ strong correlation and $r=0.8-1.0-$ a very strong correlation. Mann-Whitney $U$ test was used to analyse the control group versus patient data. The level of significance for tests was chosen as $5 \%$ and $1 \%$ ( $p$-value $<0.05$ and $<0.01$ ).

\section{Results}

All cholesteatoma routinely stained tissue showed cystic layer with anucleate keratin mass, matrix with hyperproliferative epithelium cells and perimatrix with many inflammatory cells and connective tissue (Figure 1a). Control group, tissue from deep external ear canal skin demonstrated unchanged stratified squamous epithelium and underlying connective tissue without inflammation (Figure 1b). Proliferation marker Ki-67 marked from occasional to a few positive cells in the cholesteatoma matrix, which is a statistically significant difference compared to the control group where the epithelium demonstrated from moderate to numerous Ki-67 positive cells (Table 1). Ki-67 positive cells in cholesteatoma perimatrix varied from occasional to a few and did not differ from a similar number of cells in connective tissue (Table 1). Numbers of MMP-2 positive cells displayed from absence to moderate in cholesteatoma matrix and perimatrix. In the control group epithelium, MMP-2 positive cells averaged from no to numerous, but in the connective tissue, mainly a few MMP-2 positive cells were detected. There was no statistically significant difference between the groups (Table 1) (Figures 1,2a \& 2b). However, there was a statistically significant difference between the number of TIMP-2 positive cells in the matrix (on average occasional) and control group epithelium (on average a few to moderate) (Table 1), (Figures 2c \& 2d). Cytokine IL-1 positive cells (a few to moderate) and IL-10 positive cells (moderate to numerous) displayed in all cholesteatoma patient matrix and perimatrix.

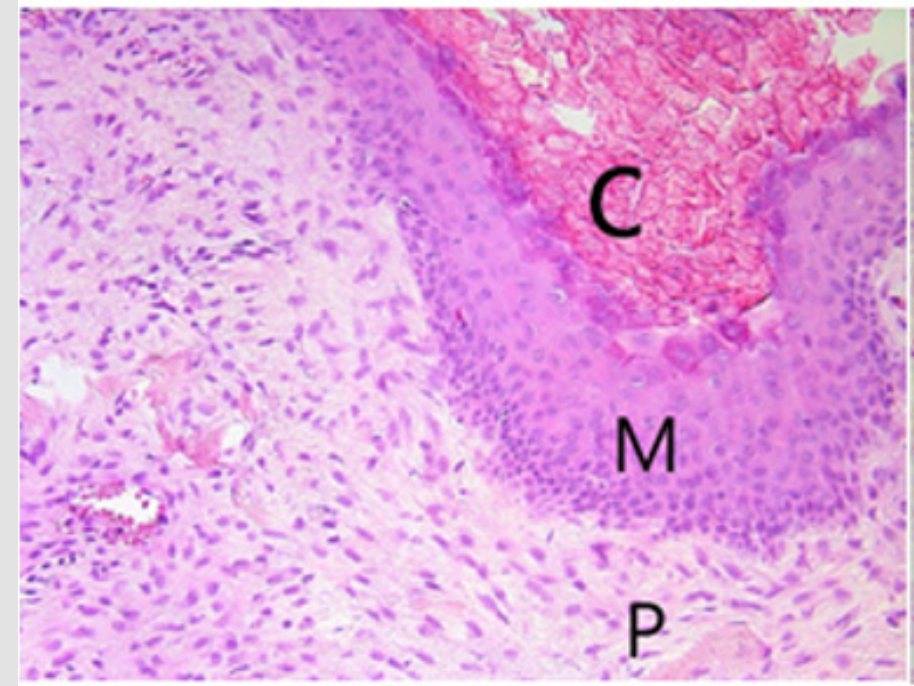

(a)

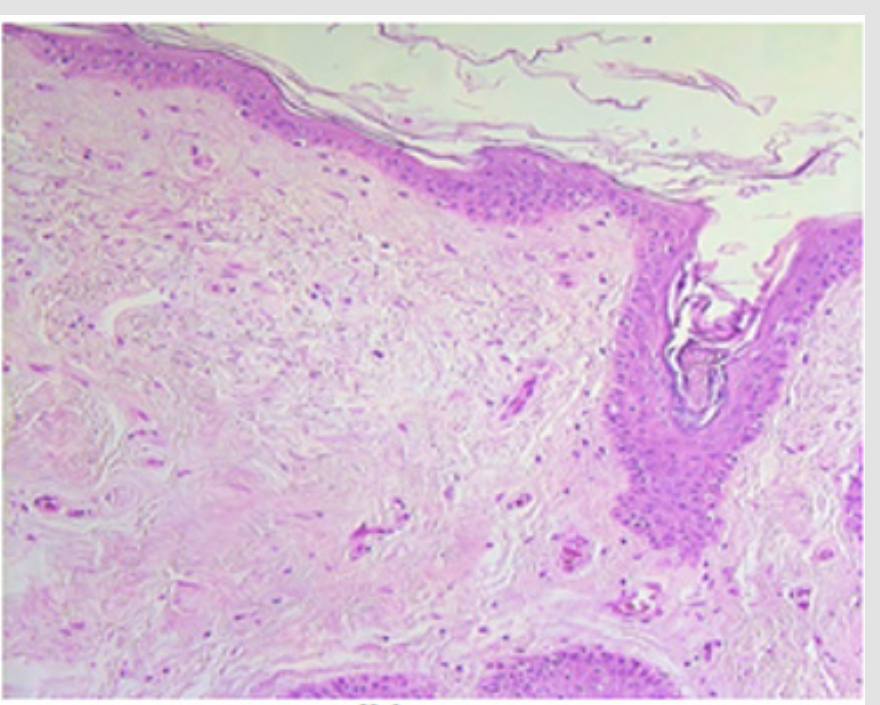

(b)

Figure 1: $(a-b)$ Micrographs of cholesteatoma and control skin tissue.

(a) Cholesteatoma in a 58 years old patient, where visible cystic layer mostly consisting of desquamated, anucleate keratin mass, matrix with hyperproliferative stratified squamous epithelium and perimatrix- inflamed subepithelial connective tissue consisting of inflammatory cells and connective tissue -. Hematoxylin and eosin, X 200;

(b) Control material - practically unchanged skin from the external ear canal. Hematoxylin and eosin, X 200.

Abbreviations: C: Cystic Layer; M: Matrix; P: Perimatrix 

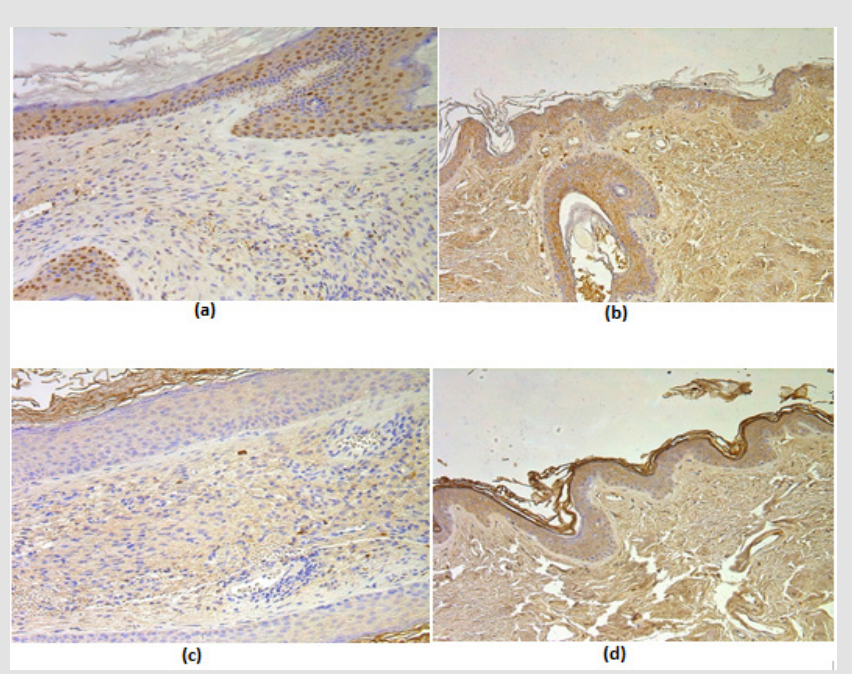

Figure 2: (a-d) Immunohistochemical micrographs of cholesteatoma tissue.

(a) A moderate number of MMP-2 positive cells in matrix and few to moderate in perimatrix of a 58 years old cholesteatoma patient. MMP-2 IHC, X 200;

(b) Numerous MMP-2 positive cells in epithelium and a few in connective tissue of a control skin sample, MMP-2 IHC, $\mathrm{X}$ 200;

(c) Few to moderate TIMP-2 positive cells in matrix and occasional in perimatrix of an 11 years old child, TIMP-2 IHC, X 200;

(d) Moderate to numerous TIMP-2 positive cells in epithelium and a few in connective tissue of a control skin sample, TIMP2 IHC, X 200.

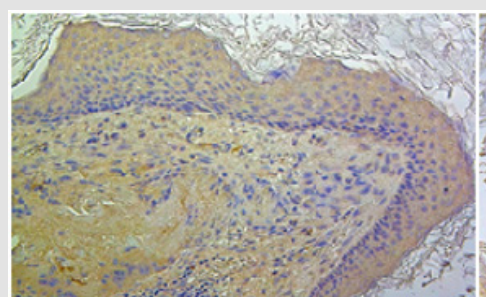

(a)

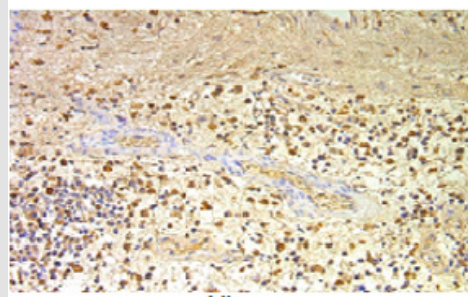

(d)

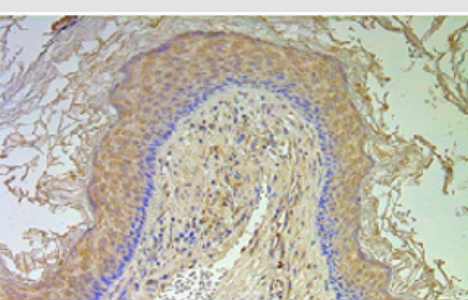

(b)

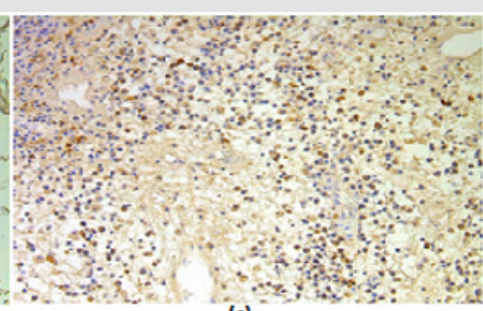

(c)

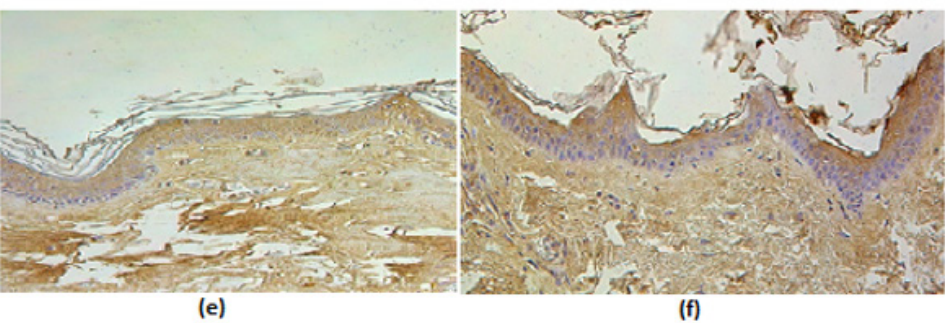

(f)

Figure 3: (a-d) Immunohistochemical micrographs of cholesteatoma tissue, (e-f) - control group.

(a) Numerous IL-1 positive cell in a matrix of a 38 years old patient. IL-1 IHC, X 200;

(b) Numerous IL-10 positive cells in a matrix of a 38 years old patient. IL-10 IHC, X200.

(c) Numerous IL-1 positive cell in perimatrix of a 23 years old patient. IL-1 IHC, X 200.

(d) Numerous IL-10 positive cells in perimatrix of a 23 years old patient. IL-10 IHC, X200.

(e) Moderate IL-1 positive cell in the epithelium and a few in the connective tissue of a control skin sample, IL-1 IHC, X 200

(f) Moderate IL-10 positive cells in the epithelium and moderate in the connective tissue of a control skin sample, IL-10 IHC, X 200

Slightly more positive cells were in matrix compared to perimatrix (Table 1), (Figures 3a-3d). There was no statistically significant difference in the number of IL-1 and IL-10 positive cells between the cholesteatoma group and control group (Table
1), (Figures 3e \& 3f). We detected that H $\beta D-2$ containing cells in matrix varied from a few to numerous. But $\mathrm{H} \beta \mathrm{D}-4$ positive cells in matrix varied from no to moderate (Table 1), (Figures 4a- 4c). In perimatrix, $\mathrm{H} \beta \mathrm{D}-2$ positive cells displayed from a few to moderate 
positive cells, but H $\beta D-4$ positive cells in perimatrix were seen from an occasional to moderate. In the control group epithelium, $\mathrm{H} \beta \mathrm{D}-2$ positive cells averaged from occasional to numerous, but in connective tissue, there were mainly no positive cells. H $\beta D$ 4 positive cells in epithelium varied from a few to moderate, but in the connective tissue on average only occasional positive cells were seen. There was a statistically significant difference between a number of $\mathrm{H} \beta \mathrm{D}-2$ and $\mathrm{H} \beta \mathrm{D}-4$ positive cells in perimatrix compared to control group connective tissue (Tables $1 \& 2$ ), (Figures $4 \mathrm{~b} \& 4 \mathrm{~d}$ ). Shh-containing cells in matrix varied from moderate to numerous, while in perimatrix mainly moderate Shh positive cells were seen (Table 1), (Figure 5a). In the control group epithelium, Shh positive cells averaged from moderate to numerous, but in connective tissue, only a few Shh positive cells were detected (Table 1), (Figure 5b).

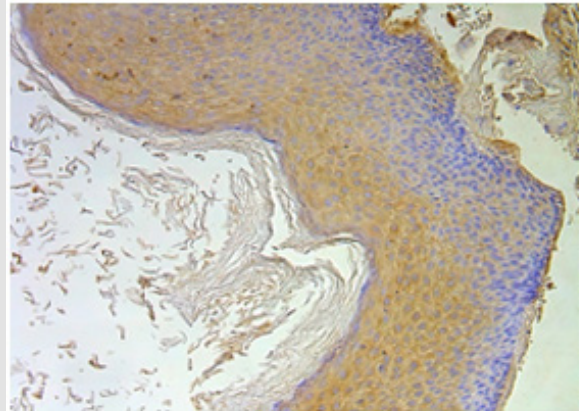

(a)

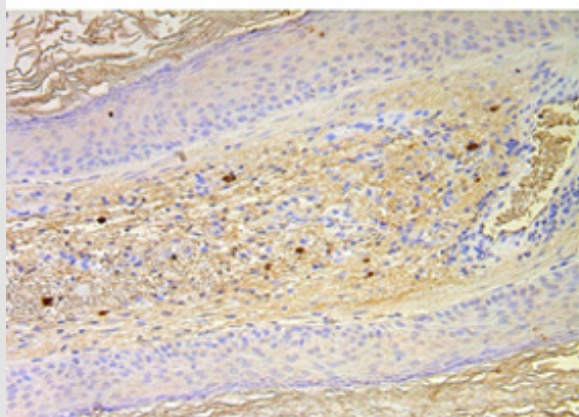

(c)

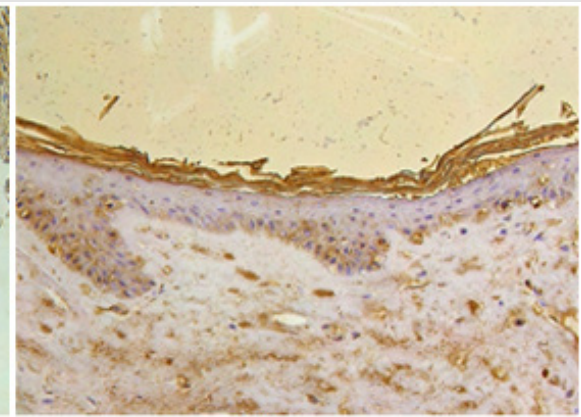

(b)

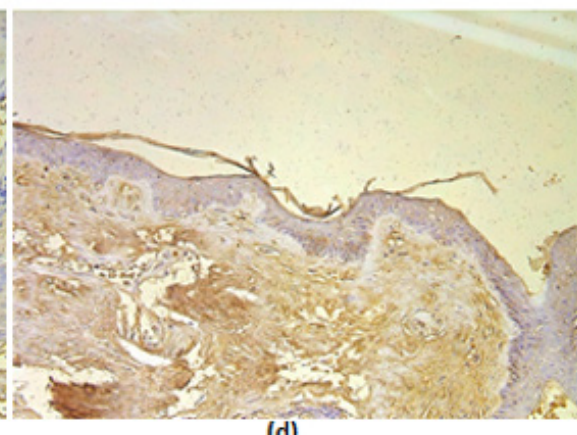

(d)

Figure 4: (a-d) Immunohistochemical micrographs of cholesteatoma tissue.

(a) Moderate to numerous H $\beta$ D-2 positive cells in a matrix of a 38 years old cholesteatoma patient. H $\beta$ D-2 IHC, X 200;

(b) Few H $\beta$ D-2 positive cells in epithelium and occasional in connective tissue of a control skin sample, H $\beta$ D-2 IHC, X 200.

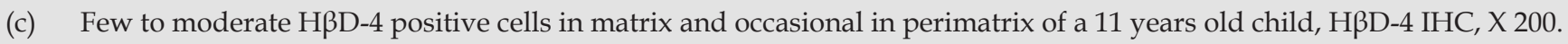

(d) Few H $\beta$ D-4 positive cells in epithelium and none in connective tissue of a control skin sample, H $\beta$ D-4 IHC, X 200.

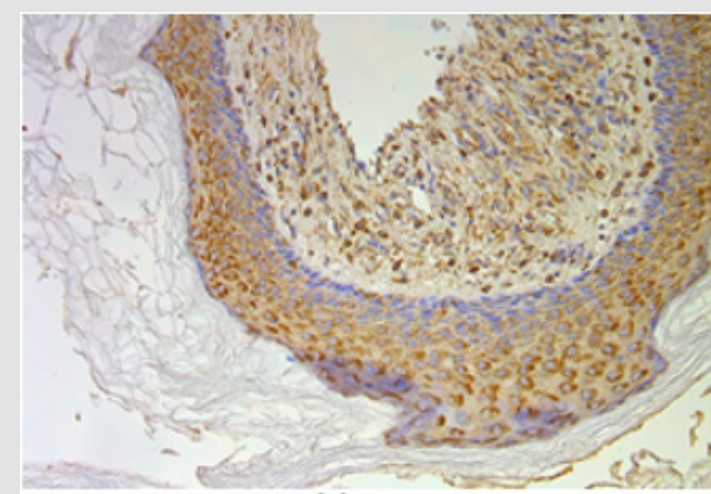

(a)

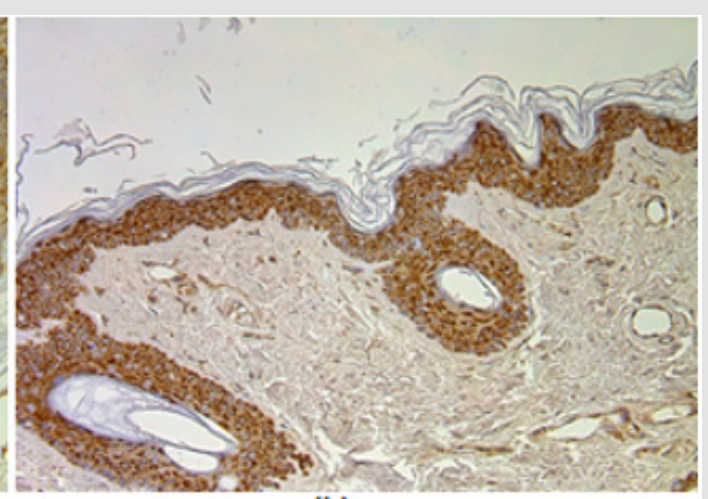

(b)

Figure 5: (a-b) Immunohistochemical micrographs of cholesteatoma tissue and control group subjects.

(a) Moderate to numerous Shh positive cells in matrix and moderate in perimatrix of a 38 years old cholesteatoma patient, Shh IHC, X 200;

(b) Numerous to abundance Shh positive cells in the epithelium and a few in the connective tissue of a control skin sample, Shh IHC, X 200. 
A statistically significant difference was seen between the number of Shh positive cells in cholesteatoma patients perimatrix and controls connective tissue (Tables 1 \& 2). A statistically significant difference was seen between the numbers of Ki-67, TIMP-2 positive cells in matrix and control group epithelium. Also, a statistically significant difference was detected between numbers of H $\beta D-2$, H $\beta D-4$ Shh positive cells in perimatrix in comparison to control group connective tissue (Table 2). A very strong positive correlation was detected in

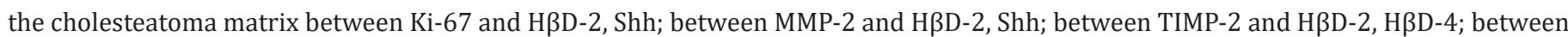

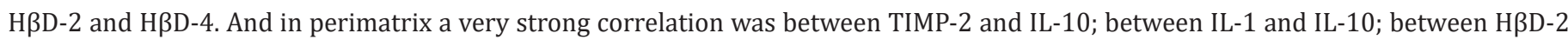
and Shh. A strong correlation was detected in matrix between Ki-67 and MMP-2, HßD-4 and between TIMP-2 and IL-1 (Table 3). A very strong positive correlation was detected in control tissue epithelium between Ki-67 and TIMP-2, IL-10, Shh; between MMP-2 and TIMP2, IL-1; between IL-10 and TIMP-2, Shh. In connective tissue, a very strong correlation was detected between Ki-67 and Shh. A strong correlation was detected in epithelium between Ki-67 and MMP-2 and between MMP-2 and IL-10 (Table 4).

Table 1: Relative numbers of different tissue factor positive structures in cholesteatoma patients and controls.

\begin{tabular}{|c|c|c|c|c|c|c|c|c|c|c|c|c|c|c|c|c|c|}
\hline $\mathbf{N}$ & Age & $\begin{array}{c}\text { Ki-67 } \\
\mathbf{M}^{*}\end{array}$ & $\begin{array}{c}\text { Ki-67 } \\
\text { P }\end{array}$ & $\begin{array}{c}\text { MMP-2 } \\
\text { M }\end{array}$ & $\begin{array}{c}\text { MMP- } \\
2 \\
\text { P }\end{array}$ & $\begin{array}{c}\text { TIMP-2 } \\
\text { M* }^{*}\end{array}$ & $\begin{array}{c}\text { TIMP- } \\
2 \\
\text { P }\end{array}$ & $\begin{array}{c}\text { IL-1 } \\
\text { M }\end{array}$ & $\begin{array}{c}\text { IL-1 } \\
\text { P }\end{array}$ & $\begin{array}{c}\text { IL-10 } \\
\text { M }\end{array}$ & $\begin{array}{c}\text { IL-10 } \\
\text { P }\end{array}$ & $\begin{array}{c}\text { HBD-2 } \\
\text { M }\end{array}$ & $\begin{array}{c}\text { HBD- } \\
2 \\
\mathrm{P}^{*}\end{array}$ & $\begin{array}{c}\text { HBD- } \\
4 \\
\text { M }\end{array}$ & $\begin{array}{c}\text { HBD- } \\
4 \\
\text { P* }\end{array}$ & $\begin{array}{c}\text { Shh } \\
\text { M }\end{array}$ & $\begin{array}{c}\text { Shh } \\
\text { P* }\end{array}$ \\
\hline P1 & 9 & 0 & 0 & 0 & 0 & 0 & 0 & $0 /+$ & + & + & + & 0 & 0 & 0 & $0 /+$ & 0 & 0 \\
\hline P2 & 11 & + & $0 /+$ & $+/++$ & $0 /+$ & $+/++$ & $0 /+$ & +++ & + & +++ & ++ & $++/+++$ & ++ & $+/++$ & $0 /+$ & $++/+++$ & ++ \\
\hline P3 & 16 & + & $0 /+$ & + & $0 /+$ & 0 & 0 & $+/++$ & + & +++ & $+/++$ & ++ & $+/++$ & $0 /+$ & + & $++/+++$ & ++ \\
\hline P4 & 17 & $0 /+$ & $00 /+$ & $0 /+$ & $0 /+$ & 0 & 0 & ++ & $0 /+$ & ++ & + & $+/++$ & + & 0 & + & $+/++$ & + \\
\hline P5 & 23 & $0 /+$ & $00 /+$ & 0 & + & $0 /+$ & $+/++$ & ++ & +++ & +++ & +++ & ++ & $+/++$ & + & $0 /+$ & ++ & ++ \\
\hline P6 & 38 & + & + & $+/++$ & $0 /+$ & $0 /+$ & $0 /+$ & +++ & $+/++$ & +++ & ++ & $++/+++$ & ++ & $+/++$ & + & $++/+++$ & ++ \\
\hline P7 & 46 & $0 /+$ & $00 /+$ & $+/++$ & $+/++$ & 0 & 0 & $+/++$ & + & +++ & + & ++ & ++ & 0 & ++ & $++/+++$ & ++ \\
\hline P8 & 58 & + & + & ++ & $+/++$ & +++ & + & $+/++$ & + & $++/+++$ & ++ & $++/+++$ & ++ & ++ & + & +++ & ++ \\
\hline P9 & 75 & $0 /+$ & + & $0 /+$ & $+/++$ & 0 & $0 /+$ & ++ & $+/++$ & $++/+++$ & +++ & ++ & $+/++$ & + & + & ++ & $+/++$ \\
\hline Avg & 32 & $0 /+$ & $0 /+$ & + & $0 /++$ & $0 /+$ & $0 /+$ & ++ & $+/++$ & $++/+++$ & ++ & ++ & $+/++$ & + & + & ++ & $+/++$ \\
\hline $\mathbf{N}$ & & $\mathbf{E}$ & CT & E & CT & $\mathbf{E}$ & CT & $\mathbf{E}$ & CT & E & CT & $\mathbf{E}$ & CT & $\mathbf{E}$ & CT & $\mathbf{E}$ & CT \\
\hline C1 & - & $0 /+$ & $00 /+$ & 0 & + & $0 /+$ & + & + & + & + & + & + & $0 /+$ & $+/++$ & $0 /+$ & 0 & 0 \\
\hline C2 & - & ++ & $0 /+$ & 0 & + & + & + & 0 & + & ++ & ++ & $0 /+$ & 0 & + & 0 & ++ & + \\
\hline C3 & - & ++ & $00 /+$ & 0 & + & + & 0 & $0 /+$ & + & ++ & ++ & $0 /+$ & 0 & ++ & $0 /+$ & $0 /+$ & 0 \\
\hline C4 & - & +++ & $0 /+$ & +++ & + & $++/+++$ & + & ++ & + & +++ & + & +++ & $0 /+$ & ++ & 0 & $+++/++++$ & + \\
\hline C5 & - & $++/+++$ & $0 /+$ & $++/+++$ & + & $++/+++$ & + & ++ & + & $++/+++$ & + & $+/++$ & $0 /+$ & ++ & + & $+++/++++$ & + \\
\hline C6 & - & ++ & $0 /+$ & $+/++$ & + & ++ & $0 /+$ & $++/+++$ & + & ++ & + & $0 /+$ & 0 & + & $0 /+$ & $+/++$ & $0 /+$ \\
\hline C7 & - & ++ & $0 /+$ & $0 /+$ & + & $+/++$ & $0 /+$ & ++ & + & ++ & + & + & 0 & + & 0 & $0 /+$ & + \\
\hline Avg & - & ++ & $0 /+$ & + & + & $+/++$ & $0 /++$ & $+/++$ & + & ++ & + & + & $00 /+$ & $+/++$ & $00 /+$ & $+/++$ & $0 /+$ \\
\hline
\end{tabular}

Abbreviations: P1-P9: Patients 1-9; C1-C7: Controls 1-7; AVG - Average; M: Matrix; P: Perimatrix; E: Epithelium; CT: Connective Tissue; Ki-67: Proliferation Marker; MMP-2: Matrix Metalloproteinase 2; TIMP-2: Tissue Inhibitor of Metalloproteinase-2; IL-1: Interleukin 1; IL-10: Interleukin 10; HßD-2: Human Beta Defensin 2; HßD-4: Human Beta Defensin 4; Shh: Sonic Hedgehog; 0/+: Occasional Positive Structures; +: Few Positive Structures; +/++: Few to Moderate Number Of Positive Structures; ++: Moderate Number of Positive Structures; ++/+++: Moderate to Numerous Positive Structures; +++: Numerous Positive Cells; +++/++++: Numerous to Abundant Structures; ++++: Abundance of Positive Structures in the Visual Field

Table 2: Mann-Whitney U test revealing statistically significant differences in cell positive factors between cholesteatoma patients and control group.

\begin{tabular}{|c|c|c|c|}
\hline Detected factor & Mann - Whitney U test & Z-Score & p-Value \\
\hline Difference between Ki-67 in cholesteatoma matrix and control tissue epithelium & 57 & 2,782 & 0,005 \\
\hline Difference between TIMP-2 in cholesteatoma matrix and control tissue epithelium & 51,5 & 2,160 & 0,031 \\
\hline Difference between $\mathrm{H} \beta \mathrm{D}-2$ in cholesteatoma perimatrix and control connective tissue & 5 & $-2,887$ & 0,003 \\
\hline Difference between $\mathrm{H} \beta \mathrm{D}-4$ in cholesteatoma perimatrix and control connective tissue & 10 & $-2,411$ & 0,023 \\
\hline Difference between Shh in cholesteatoma perimatrix and control connective tissue & 8 & $-2,603$ & 0,012 \\
\hline
\end{tabular}

Abbreviations: Ki-67: Proliferation Marker; TIMP-2: Tissue Inhibitor of Metalloproteinase 2; H $\beta$ D-2: Human Beta Defensin 2; HßD-4: Human Beta Defensin 4; Shh: Sonic Hedgehog 
Table 3: Spearman's rank correlation coefficient revealed correlations between the relative numbers of different tissue factors in cholesteatoma matrix and perimatrix.

\begin{tabular}{|c|c|c|c|}
\hline Factor 1 & Factor 2 & $\mathbf{R}$ & $P$ - value \\
\hline \multicolumn{4}{|c|}{ A Very Strong Positive Correlation } \\
\hline Ki-67 in matrix & $\mathrm{H} \beta \mathrm{D}-2$ in matrix & 0,855 & 0,003 \\
\hline Ki-67 in matrix & Shh in matrix & 0,843 & 0,004 \\
\hline MMP-2 in matrix & $\mathrm{H} \beta \mathrm{D}-2$ in matrix & 0,801 & 0,010 \\
\hline MMP-2 in matrix & Shh in matrix & 0,915 & 0,001 \\
\hline TIMP-2 in matrix & $\mathrm{H} \beta \mathrm{D}-2$ in matrix & 0,815 & 0,007 \\
\hline TIMP-2 in matrix & $\mathrm{H} \beta \mathrm{D}-4$ in matrix & 0,885 & 0,002 \\
\hline $\mathrm{H} \beta \mathrm{D}-2$ in matrix & $\mathrm{H} \beta \mathrm{D}-4$ in matrix & 0,901 & 0,001 \\
\hline TIMP-2 in perimatrix & IL-10 in perimatrix & 0,876 & 0,002 \\
\hline IL-1 in perimatrix & IL-10 in perimatrix & 0,806 & 0,009 \\
\hline $\mathrm{H} \beta \mathrm{D}-2$ in perimatrix & Shh in perimatrix & 0,822 & 0,007 \\
\hline \multicolumn{4}{|c|}{ Strong Positive Correlation } \\
\hline Ki-67 in matrix & MMP-2 in matrix & 0,763 & 0,017 \\
\hline Ki-67 in matrix & $\mathrm{H} \beta \mathrm{D}-4$ in matrix & 0,740 & 0,023 \\
\hline TIMP-2 in perimatrix & IL-1 in perimatrix & 0,674 & 0,047 \\
\hline
\end{tabular}

Abbreviations: Ki-67: proliferation marker; MMP-2: matrix metalloproteinase 2; TIMP-2: tissue inhibitor of metalloproteinase-2; IL-1: interleukin 1; IL-10: interleukin 10; HßD-2: Human beta defensin 2; H $\beta$ D-4: Human beta defensin 4; Shh: Sonic hedgehog

Table 4: Spearman's rank correlation coefficient revealed correlations between the relative numbers of different tissue factors in control tissue epithelium and connective tissue.

\begin{tabular}{|c|c|c|c|}
\hline \multicolumn{1}{|c|}{ Factor 1 } & Factor 2 & R & P - value \\
\hline \multicolumn{4}{|c|}{ A Very Strong Positive Correlation } \\
\hline Ki-67 in epithelium & TIMP-2 in epithelium & 0,903 & 0,005 \\
\hline Ki-67 in epithelium & IL-10 in epithelium & 1 & 0 \\
\hline Ki-67 in epithelium & Shh in epithelium & 0,903 & 0,005 \\
\hline MMP-2 in epithelium & TIMP-2 in epithelium & 0,943 & 0,001 \\
\hline MMP-2 in epithelium & IL-1 in epithelium & 0,816 & 0,025 \\
\hline IL-10 in epithelium & TIMP-2 in epithelium & 0,903 & 0,005 \\
\hline IL-10 in epithelium & Shh in epithelium & 0,903 & 0,009 \\
\hline Ki-67 in connective tissue & Shh in connective tissue & 0,882 & \\
\hline \multicolumn{2}{|c|}{ Strong Positive Correlation } & 0,033 \\
\hline Ki-67 in epithelium & MMP-2 in epithelium & 0,795 & 0,033 \\
\hline MMP-2 in epithelium & IL-10 in epithelium & 0,795 & \\
\hline
\end{tabular}

Abbreviations: Ki-67: Proliferation Marker; MMP-2: Matrix Metalloproteinase 2; TIMP-2: Tissue Inhibitor of Metalloproteinase-2; IL-1: Interleukin 1; IL-10: Interleukin 10; Shh: Sonic hedgehog

\section{Discussion}

In the present study, we found a statistically significant difference in numbers of the proliferation marker Ki-67 positive cells in cholesteatoma matrix compared to skin epithelium. Our data shows overexpression of Ki-67 positive cells in control group epithelium compared to cholesteatoma matrix. That probably might suggest the specific stage of disease with a decrease in cellular activity. However, this data was different from other studies where Chung et al. [35] and Hamed et al. [36] proved overexpression of Ki67 in cholesteatoma tissue compared to skin epithelium. This might be explained by the fact that Hamed and other authors took control skin from the same patients, who had cholesteatoma. We, on the other hand, took control skin from different specimens, which were not related to cholesteatoma. The ununiform appearance of different defensins in cholesteatoma more likely linked to the specificity of tumour development. In the present study, we show more H $\beta D-2$ positive cells in cholesteatoma compared to H $\beta D$ 4. It might suggest that $\mathrm{H} \beta \mathrm{D}-2$ is a stronger antimicrobial factor that $\mathrm{H} \beta \mathrm{D}-4$ in cholesteatoma. We proved a very strong correlation between both beta defensins in cholesteatoma matrix. 
There was no such correlation in the control group. This finding shows that H $\beta D-2$ and H $\beta D-4$ affect each other in the chronic inflammation process. The present study shows a statistically significant difference between H $\beta$ D- 2 and H $\beta D-4$ in cholesteatoma perimatrix comparing to control group. It proves that inflammatory

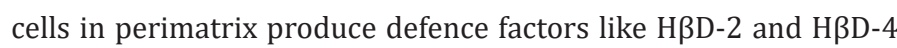
to fight chronic inflammation. These findings overlap with other author data, where Song et al. [37] and Park et al. [23] prove overexpression of H $\beta \mathrm{D}-2$ in cholesteatoma compared to the control skin tissue. However, the present study is the first, which shows $\mathrm{H} \beta \mathrm{D}-4$ overexpression in cholesteatoma tissue compared to a control group. Our data shows a very strong correlation between Ki-

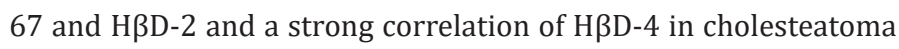
matrix. There is no similar correlation in the control group. Thus, we speculate on the interrelation between the proliferation of cells and notable release of antimicrobial proteins to suppress chronic inflammation in middle ear. There was no statistical difference between MMP-2 in cholesteatoma and the control group, which also is similar to other author data (Banerjee et al.) [13].

However, more TIMP-2 positive cells were found in the control group tissue compared to the patient group, and it was statistically significant, which might suggest that TIPM-2 in cholesteatoma is suppressed and therefore an osteolytic process in the middle ear is induced by MMPs [12]. Even though there is no statistically significant difference between groups in cytokines IL-1 and IL10, slightly more IL-1 and IL-10 positive cells are in the patient group. This data is similar to Yetiser et al. [38] and Kuczkowski et al. [20], where they show increased IL-1 activity in cholesteatoma. We support that pro- and anti-inflammatory balance seems to be very stable in the tumour tissue that is proved by a very strong correlation between IL-1 and IL-10 in perimatrix. Our data showed that Shh gene protein was statistically significantly more expressed in cholesteatoma perimatrix than in the control group. Other researchers like Jiang et al. [39-41] proved that mutations in Shh gene can cause multiple embryogenetic anomalies and even cancer development [42]. The ongoing study authors suggest the Shh gene might play a major role in the development of cholesteatoma. Further investigations of the Shh gene in the molecular level might give more precise information about the gene involved in the development of cholesteatoma.

\section{Conclusion}

Cholesteatoma tissue with the low appearance of Ki-67 proves the indistinct proliferation activity in the already developed tumour,

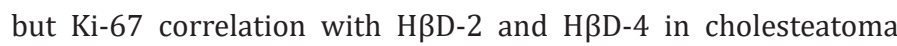
indicate a direct link between the proliferation and expression of antimicrobial peptides. From defensins, HBD-2 seems to be the most important factor for antimicrobial defence, but the correlation between H $\beta D-2$ and H $\beta$ D-4 suggest their common action against chronic middle ear infection in case of choleasteatoma. Higher levels of MMP-2 positive cells in cholesteatoma and lower levels of TIMP-
2 positive cells suggest a prevalence of enzymatic processes over their suppression, possibly being characteristic for cholesteatoma of different age patients. The lower IL- 1 and higher IL-10 positive structure relation indicate the correct balance between pro- and anti-inflammatory cytokines in cholesteatoma. The prevalence of the Shh gene in the specific layers of the tumour might play a crucial role in the common development of cholesteatoma.

\section{References}

1. Maniu A, Harabagiu O, Perde Schrepler M, Cătană A, Fănuță B, et al. (2014) Molecular biology of cholesteatoma. Rom J Morphol Embryol 55(1): 7-13.

2. Yung M, Tono T, Olszewska E, Yamamoto Y, Sudhoff H, et al. (2017) EAONO/JOS Joint Consensus Statements on the Definitions, Classification and Staging of Middle Ear Cholesteatoma. J Int Adv Otol 13(1): 1-8.

3. Kemppainen HO, Puhakka HJ, Laippala PJ, Sipila MM, Manninen MP, et al. (1999) Epidemiology and etiology of middle ear cholesteatoma. Acta Otolaryngol 119(5): 568-572.

4. Lim DJ, Saunders WH (1972) Acquired cholesteatoma: light and electron microscopic observations. Annals of Otology, Rhinology and Laryngology 81(1): 1-11.

5. Zarandy MM, Rutka J (2010) Cholesteatoma and its complications. In: Diseases of the Inner Ear: A Clinical, Radiologic, and Pathologic Atlas. Springer: Berlin, Heidelberg, Germany.

6. Mallet Y, Nouwen J, Lecomte Houcke M, Desaulty A (2003) Aggressiveness and quantification of epithelial proliferation of middle ear cholesteatoma by MIB1. Laryngoscope 113(2): 328-331.

7. Bujıa J, Kim C, Holly A, Sudhoff H, Ostos P, et al. (1996) Epidermal growth factor receptor (EGF-R) in human middle ear cholesteatoma: an analysis of protein production and gene expression. Am J Otol 17(2): 203-206.

8. Schmidt M, Grünsfelder P, Hoppe F (2000) Induction of matrix metalloproteinases in keratinocytes by cholesteatoma debris and granulation tissue extracts. Eur Arch Otorhinolaryngol 257(8): 425-429.

9. Hadler Olsen E, Fadnes B, Sylte I, Uhlin Hansen L, Winberg JO (2011) Regulation of matrix metalloproteinase activity in health and disease. FEBS J 278(1): 28-45.

10. Butler GS, Overall CM (2009) Updated biological roles for matrix metalloproteinases and new "intracellular" substrates revealed by degradomics. Biochemistry 48(46): 10830-10845.

11. Sbardella D, Fasciglione GF, Gioia M, Ciaccio C, Tundo GR, et al. (2012) Human matrix metalloproteinases: an ubiquitarian class of enzymes involved in several pathological processes. Mol Aspects Med 33(2): 119208.

12. Morales DSR, De Oliveira Penido N, Da Silva IDCG, Stávale JN, Guilherme A, et al. (2007) Matrix Metalloproteinase 2: an important genetic marker for cholesteatomas. Brazilian Journal of Otorhinolaryngology 73(1): 5157.

13. Banerjee AR, James R, Narula AA (1998) Matrix metalloproteinase-2 and matrix metalloproteinase-9 in cholesteatoma and deep meatal skin. Clin Otolaryngol Allied Sci 23(4): 345-347.

14. Dornelles C de C, Da Costa SS, Meurer L, Rosito LP, Da Silva AR, et al. (2009) Comparison of acquired cholesteatoma between pediatric and adult patients. Eur Arch Otorhinolaryngol 266(10): 1553-1561.

15. Schönermark M, Mester B, Kempf HG, Bläser J, Tschesche H, et al. (1996) Expression of matrix-metalloproteinases and their inhibitors in human cholesteatomas. Acta Otolaryngol 116(3): 451-456.

16. Abramson M, Moriyama H, Huang CC (1984) Pathogenic factor in bone resorption in cholesteatoma. Acta Otolaryngol 97(5-6): 437-442.

17. Ahn JM, Huang CC, Abramson M (1990) Localisation of interleukin-1 in human cholesteatoma. Am J Otolaryngol 11(2): 71-77. 
18. Nason R, Jung JY, Chole RA (2009) Lipopolysaccharide-induced osteoclastogenesis from mononuclear precursors: a mechanism for osteolysis in chronic otitis. J Assoc Res Otolaryngol 10(2): 151-160.

19. Wei S, Kitaura ZP, Ross FP, Teitelbaum SL (2005) IL-1 mediates TNFinduced osteoclastogenesis. J Clin Invest 115(2): 282-290.

20. Kuczkowski J, Sakowicz Burkiewicz M, Iżycka Świeszewska E, Mikaszewski B, Pawełczyk T (2011) Expression of Tumor Necrosis Factor-alfa, Interleukin-1alfa, Interleukin-6 and Interleukin-10 in Chronic Otitis Media with Bone Osteolysis. ORL J Ortho Relat73(2): 9399.

21. Brook I (1981) Aerobic and anearobic bacteriology of cholesteatoma Laryngoscope 91(2): 250-253.

22. Harder J, Meyer Hoffert U, Teran LM, Schwichtenberg L, Bartels J, et al. (2000) Mucoid Pseudomonas aeruginosa, TNF-alpha, and IL- 1beta, but not IL-6, induce human beta-defensin-2 in respiratory epithelia. Am J Respir Cell Mol Biol 22(6): 714-721.

23. Park K, Moon SK, Choung YH, Choi HS (2003) Expression of betadefensins in human middle ear cholesteatoma. Acta Otolaryngol 123(2): 236-240.

24. Prahl A, Pazgier M, Alexandratos J, Lubkowski J (2016) Human $\beta$-defensin 4 - defensin without the "twist". Postępy Biochemii 62(3): 349-361.

25. Smiley AK, Gardner J, Klingenberg JM, Neely AN, Supp DM (2007) Expression of human beta defensin 4 in genetically modified keratinocytes enhances antimicrobial activity. J Burn Care Res 28(1): 127-132.

26. Yanagi S, Ashitani J, Ishimoto H, Date Y, Mukae H, et al. (2005) Isolation of human $\beta$-defensin-4 in lung tissue and its increase in lower respiratory tract infection. Respiratory Res 6(1): 130.

27. García JR, Krause A, Schulz S, Rodríguez Jiménez FJ, Klüver E, et al. (2001) Human $\beta$-defensin 4: a novel inducible peptide with a specific salt-sensitive spectrum of antimicrobial activity. FASEB J 15(10): 1819 1821.

28. Lange W (1932) Tief eingezogene Membrana flaccida und cholesteatom Z. Hals, Nasen, Ohrenheilk 30: 575Y82.

29. Bowden REM (1977) Development of the middle and external ear in man. Proc Roy Soc Med 70(11): 807-815.

30. Ahlgren SC, Bronner Fraser M (1999) Inhibition of sonic hedgehog signaling in vivo results in craniofacial neural crest cell death. Curr Biol 9(22): 1304-1314.

ISSN: 2574-1241

DOI: $10.26717 /$ BJSTR.2020.24.004039

Kristaps Dambergs. Biomed J Sci \& Tech Res

CC This work is licensed under Creative

Commons Attribution 4.0 License

Submission Link: https://biomedres.us/submit-manuscript.php
31. Brito JM, Teillet MA, le Douarin NM (2006) An early role for sonic hedgehog from foregut endoderm in jaw development: Ensuring neural crest cell survival. Proc Natl Acad Sci 103(31): 11607-11612.

32. Brito JM, Teillet MA, le Douarin NM (2008) Induction of mirror-image supernumerary jaws in chicken mandibular mesenchyme by sonic hedgehog-producing cells. Development 135: 2311-2319.

33. Wright CG (1997) Development of the Human External Ear. Journal of the American Academy of Audiology 8(6): 379-382.

34. Pilmane M, Rumba I, Sundler F, Luts A (1998) Patterns of distribution and occurrence of neuroendocrine elements in lungs of humans with chronic lung disease. Proc Latv Acad Sci 52: 144-152.

35. Chung JH, Lee SH, Park CW, Kim KR, Tae K, et al. (2015) Expression of apoptotic vs antiapoptotic proteins in middle ear cholesteatoma. Otolaryngol Head Neck Surg 153(6): 1024-1030.

36. Hamed MA, Nakata S, Shiogama K, Suzuki K, Sayed RH, et al. (2017) Cytokeratin 13, Cytokeratin 17, and Ki-67 expression in human acquired cholesteatoma and their correlation with its destructive capacity. Clin Exp Otorhinolaryngol 10(3): 213-220.

37. Song JJ, Chae SW, Woo JS, Lee HM, Jung HH, et al. (2007) Differential expression of human beta defensin 2 and human beta defensin 3 in human middle ear cholesteatoma. Ann Otol Rhinol Laryngol 116(3): 235-240.

38. Yetiser S, Satar B, Aydin N (2002) Expression of epidermal growth factor, tumor necrosis factor- $\alpha$, and interleukin- $1 \alpha$ in chronic otitis media with or without cholesteatoma. Otol Neurotol 23(5): 647-652.

39. Jiang J, Hui CC (2008) Hedgehog signaling in development and cancer. Dev Cell 15(6): 801-812.

40. Dessaud E, Mc Mahon AP, Briscoe J (2008) Pattern formation in the vertebrate neural tube: a sonic hedgehog morphogen-regulated transcriptional network. Development 135(15): 2489-2503.

41. Hui CC, Angers S (2011) Gli proteins in development and disease. Annu Rev Cell Dev Biol 27: 513-537.

42. Walter K, Omura N, Hong SM, Griffith M, Vincent A, et al. (2010) Overexpression of Smoothened activates the Sonic Hedgehog signalling pathway in pancreatic cancer-associated fibroblasts. Clin Cancer Res 16(6): 1781-1789.

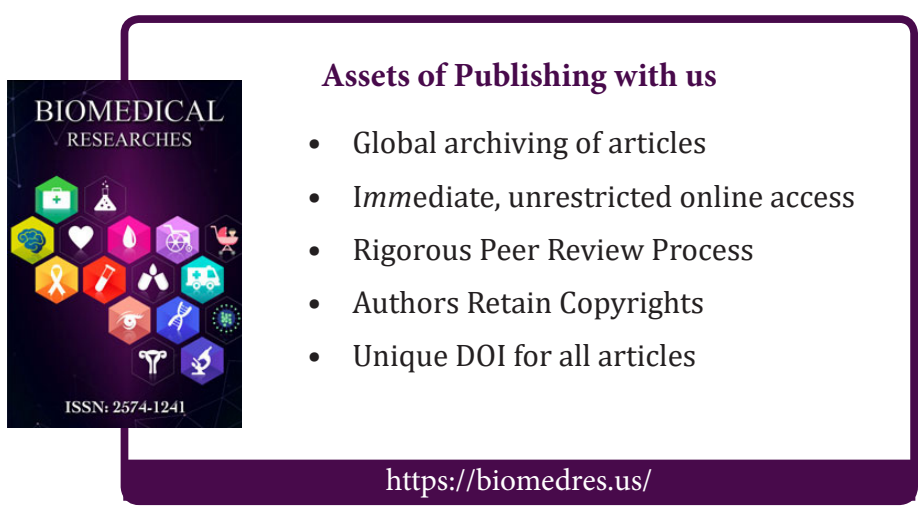

